\title{
RESEARCH
}

\section{Prevalence of methylphenidate use among Canadian children following parental divorce}

\author{
Lisa A. Strohschein
}

\section{ABSTRACT}

Background: Evidence suggests that children living in singleparent or step-parent households are more likely than children in households with 2 biological parents to be prescribed methylphenidate. I conducted a study of prospective data to investigate parental divorce as a predictor of methylphenidate use.

Methods: I used data for children who participated in the National Longitudinal Survey of Children and Youth from 1994 to 2000 . The sample was restricted to children who remained in the survey in 2000 and who, at initial interview, lived in a household with 2 biological parents $(n=4784)$. A generalized estimating equation model was used to compare the odds ratios of methylphenidate use among children whose parents obtained a divorce between 1994 and 2000 relative to children whose parents remained married during this period.

Results: Between 1994 and 2000, 633 children (13.2\%) experienced the divorce of their parents. The proportion of children who received methylphenidate at any time between 1994 and 2000 was $3.3 \%$ among those whose parents remained married and $6.1 \%$ among those whose parents divorced during this period. After adjustment for age of the mother and sex and age of the child, I found that methylphenidate use was significantly higher among children whose parents subsequently divorced than among those whose parents remained married (odds ratio 1.82, 95\% confidence interval 1.01-3.33).

Interpretation: The increased risk of children receiving a prescription for methylphenidate in the period following parental divorce raises questions about the causal links in this association. Future research is needed to replicate these findings and to investigate possible explanations.

$C M A J$ 2007;176(I2):I7II-4

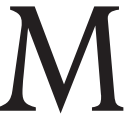
ethylphenidate is a psychostimulant drug most commonly prescribed for the treatment of attention-deficit hyperactivity disorder in children., ${ }^{1,2}$ The rapid growth of methylphenidate use over the past few decades has been documented in numerous countries, including the United States, ${ }^{3,4}$ Canada, ${ }^{5,6}$ the Netherlands, ${ }^{7}$ Is- rael $^{8}$ and Australia, ${ }^{9}$ although a recent study has noted a levelling off in use in the United States. ${ }^{10}$ These prescribing patterns have raised concerns as to whether methylphenidate is overprescribed or prescribed inappropriately to children. ${ }^{11-13}$ Assessing specific family characteristics that increase a child's chances of being prescribed the drug is a means for researchers to investigate whether its usage is appropriate.

Although researchers have reported that children living in single-parent ${ }^{14,15}$ or step-parent $t^{15,16}$ households are more likely than children in households with 2 biological parents to be prescribed methylphenidate, such findings do not reveal why living in a household without 2 biological parents is associated with an increased risk of methylphenidate use. The increased frequency of births outside of marriage in Western countries $^{17,18}$ makes it possible for children to live in singleor step-parent households without ever having experienced parental divorce. Distinguishing between living in a particular family structure and experiencing parental divorce is important because of the potentially different causal pathways involved. Families headed by mothers who have never married are at increased risk of being poor, and higher rates of methylphenidate use may be a result of the link between poverty and child mental health problems. ${ }^{19,20}$ In contrast, losing a parent through divorce is viewed as a stressful event that may challenge child-coping processes. Experiencing parental divorce has been associated with subsequent increases in child behavioural problems,${ }^{21-23}$ which might in turn be associated with an increased risk of receiving a prescription for methylphenidate. Furthermore, elevated rates of methylphenidate use among children in step-parent households may represent the persisting mental health consequences of an earlier parental divorce. As such, studies that can track the effects of family transitions as they unfold provide greater insight into the dynamic links between family processes and child outcomes.

To determine whether parental divorce subsequently increases the probability a child will be prescribed methylphenidate, researchers would need to design a prospective study to track children in households with 2 biological parents over time and the rates of methylphenidate use compared among those whose parents divorce during the study period with rates among those whose parents remain married. My search of MEDLINE, CINAHL, PsycINFO and Sociological Abstracts revealed no studies that specifically investi- 
gated the effect of parental divorce on methylphenidate use among children. I therefore sought to demonstrate that parental divorce is a risk factor for methylphenidate use by analyzing data from a prospective longitudinal study involving Canadian children.

\section{Methods}

Begun in 1994, the National Longitudinal Survey of Children and Youth is an ongoing survey conducted every other year for the purpose of tracking the development, health and well-being of a nationally representative sample of Canadian children over time. Of 15579 households identified in 1994 as having at least I dependent child under the age of 12 years, I3 439 households agreed to participate in the survey, for a response rate of $86.3 \%$. Typically, I child was randomly selected from each household, with up to 4 siblings selected in some households, which resulted in information gathered on 22 83I children in 1994. Because of sample restrictions after this first cycle (children who participated in another national survey were selected into the first cycle of the National Longitudinal Survey of Children and Youth but were not reinterviewed), the longitudinal sample comprises 16903 children who were II years old or younger in 1994 living in II I 42 households; $84.5 \%$ of these children participated in the fourth cycle of data collection (2000 survey). ${ }^{24}$

I restricted the sample for my study to children who participated in the first 4 cycles of the National Longitudinal Survey of Children and Youth and who, at the time of the initial interview in I994, were living in a household with 2 biological parents (married or common-law relationship) and were between the ages of 2 and $7(n=5099)$. This age restriction ensured that the children would pass through the ages when methylphenidate is most likely to be prescribed. ${ }^{25,26}$ I excluded children whose families reported a period of separation before I994 ( $n=25)$ and children who were already taking methylphenidate in $1994(n=83)$. Because parental death is a fun-

Table 1: Demographic characteristics of 4784 children in 3883 households whose parents remained married or divorced between 1994 and 2000*

\begin{tabular}{|c|c|c|}
\hline Variable & $\begin{array}{c}\text { Parents remained } \\
\text { married }\end{array}$ & $\begin{array}{c}\text { Parents divorced } \\
\text { by } 2000\end{array}$ \\
\hline No. (\%) of children & $4151(86.8)$ & $633(13.2)$ \\
\hline No. (\%) of households & $3362(86.6)$ & $521(13.4)$ \\
\hline \multicolumn{3}{|l|}{$\begin{array}{l}\text { Age in 1994, yr, mean } \\
(95 \% \mathrm{Cl})\end{array}$} \\
\hline Child & $4.5 \quad(4.4-4.5)$ & $4.1(4.0-4.3)$ \\
\hline Mother & $34.0(33.8-34.2)$ & $32.4(32.0-32.8)$ \\
\hline $\begin{array}{l}\text { Male sex, \% of children, } \\
\text { mean }(95 \% \mathrm{Cl})\end{array}$ & 50.4 (48.9-51.9) & $47.5(43.6-51.4)$ \\
\hline $\begin{array}{l}\text { Methylphenidate use } \\
\text { during } 1994-2000, \% \text { of } \\
\text { children, mean }(95 \% \text { Cl) }\end{array}$ & $3.3(2.7-3.8)$ & $6.1 \quad(4.2-7.9)$ \\
\hline
\end{tabular}

Note: $\mathrm{Cl}=$ confidence interval.

*Data were obtained for children who participated in the first 4 cycles (1994 to 2000) of the biennial National Longitudinal Survey of Children and Youth. damentally different event than divorce, I also excluded 34 children who had a parent die. Children for whom data on methylphenidate use were missing were also excluded, for a final sample of 4784 children within 3883 households.

The dependent variable (methylphenidate use) was considered to have been present if, at any time between 1994 and 2000, the parent reported that their child used the drug, and absent if, at each survey, the parent reported that their child was not taking the drug. Parental divorce was considered to have occurred if, between 1994 and 2000, it was reported to have taken place, and not to have occurred if the parents remained married during this period. The ages of the child and mother in 1994 were analyzed as continuous variables, measured in years.

A generalized estimating equation model was used to evaluate whether children whose parents divorced between 1994 and 2000 were more likely than children whose parents remained married to be prescribed methylphenidate. As in logistic regression, the outcome is binary; however, the generalized estimating equation model allows for observations within the same household to be correlated and produces the appropriate standard errors. The models controlled for age and sex of the child as well as the age of the mother in 1994.

The data were weighted up to the population according to Statistics Canada procedures to adjust for unequal probabilities of selection due to the multistage sampling strategy as well as attrition from the sample over time.

\section{Results}

Between 1994 and 2000, 633 children ( $13.2 \%$ ) in $52 \mathrm{I}$ households experienced the divorce of their parents (Table I). The sex of the child was unrelated to parental divorce. Children whose parents remained married were older in 1994 and had older parents than did children whose parents later divorced. This difference is not surprising given that the risk of divorce is highest during the early years of a marriage. The frequency of methylphenidate use during the study period was significantly higher among children whose parents divorced between 1994 and 2000 than among those whose parents remained married.

The generalized estimating equation model showed that boys were significantly more likely than girls to be prescribed methylphenidate during the study period (adjusted odds ratio 2.34, $95 \%$ confidence interval I.33-4.09) (Table 2). It also showed that children whose parents divorced between 1994 and 2000 were significantly more likely than those whose

Table 2: Association between likelihood of methylphenidate prescription during 1994-2000 and demographic characteristics

\begin{tabular}{lc}
\hline Characteristic & Adjusted OR $(95 \% \mathrm{Cl})^{*}$ \\
\hline Child's age in 1994 & $1.04(0.91-1.19)$ \\
Mother's age in 1994 & $0.95(0.90-1.01)$ \\
Male child & $2.34(1.33-4.09)$ \\
Parental divorce by 2000 & $1.82(1.01-3.33)$ \\
\hline
\end{tabular}

Note: $\mathrm{OR}=$ odds ratio, $\mathrm{Cl}=$ confidence interval.

*Adjusted for other variables in the table. 
parents remained married to be prescribed the drug (adjusted odds ratio $\mathrm{I} .82,95 \%$ confidence interval I.0I-3.33). Interactions between all variables in the model were tested. The interaction terms were not statistically significant and were consequently removed from the model.

In a subgroup analysis of data for the 633 children whose parents divorced between 1994 and 2000, the frequency of methylphenidate use did not differ significantly between the 2 Io children $(33.2 \%)$ who experienced a subsequent transition into a step-parent household and those whose parents did not remarry.

\section{Interpretation}

My analysis of the prospective data for a sample of children living with 2 biological parents in 1994 showed that children whose parents divorced between 1994 and 2000 were more likely than those whose households remained intact to be prescribed methylphenidate. These findings are consistent with those from studies showing that living in a household without 2 biological parents is a risk factor for methylphenidate use, ${ }^{14-16}$ and they build on this research by showing that divorce itself is a predictor of subsequent methylphenidate use.

It is possible that the stress of divorce subsequently elevated child behavioural problems to a point that necessitated methylphenidate use. However, one cannot rule out alternative explanations. First, there is evidence that attentiondeficit hyperactivity disorder has a genetic component, ${ }^{27,28}$ which suggests either direct transmission from parents to their children or an indirect tendency of parents with a history of mental health problems to divorce. Until more is known about the pathophysiology of attention-deficit hyperactivity disorder, researchers will continue to face challenges in disentangling the complex pathways through which shared genetic and environmental influences lead to this disorder and methylphenidate use. ${ }^{29}$

A second possible explanation is that, although clinicians are advised to distinguish between the symptoms of attention-deficit hyperactivity disorder and the effects of stressors such as parental divorce on child behaviour, ${ }^{30}$ a prescription for methylphenidate may result simply from increased contact with the health care system in the period following divorce or the heightened sensitivity of parents and clinicians to problematic child behaviour in the presence of stressors. This explanation suggests that methylphenidate is prescribed inappropriately to children whose parents have recently divorced. Unfortunately, there are no questions in the National Longitudinal Survey of Children and Youth that allow for testing of these causal pathways. Therefore, the findings of my study cannot reveal whether methylphenidate is inappropriately prescribed to children of divorce.

One limitation of this study is that the parents were not asked whether their child had been prescribed treatments other than methylphenidate for a mental disorder in general, or for attention-deficit hyperactivity disorder in particular. In addition, questions were restricted to a child's use of methylphenidate at the time of each survey cycle, which makes it im- possible to determine whether use of the drug was started and stopped in the period between surveys. These limitations are unlikely to change the results of this study, but they may provide additional insight into how children come to be prescribed methylphenidate. Finally, to the extent that parents with a high-conflict divorce may be more likely to drop out of the survey than parents with less contentious divorces, my estimates may represent a conservative estimate of the effects of parental divorce on rates of methylphenidate use.

Methylphenidate use did not differ significantly between the children of divorced parents who remarried and those whose divorced parents did not remarry. However, given that half of all children whose parents divorce will later become part of a step-parent household, ${ }^{31}$ conducting such comparisons in this study may have been premature and should be investigated over a longer period.

Future research is needed to replicate the results of this study and to find explanations for the increased likelihood of a child being prescribed methylphenidate following parental divorce. Such findings will help shed light on the ways in which family dynamics are linked to child health and methylphenidate use.

\section{This article has been peer reviewed.}

From the Department of Sociology, University of Alberta, Edmonton, Alta.

Competing interests: None declared.

Acknowledgements: I thank Rachel Campbell for data analysis and Claire Pitcher for library assistance.

This research was supported by grant 512-2003-I0I6 from the Social Sciences and Humanities Research Council of Canada and a Support for the Advancement of Scholarship grant from the University of Alberta.

\section{REFERENCES}

I. Lefever GB, Dawson KV, Morrow AL. The extent of drug therapy for attention deficit-hyperactivity disorder among children in public school. Am J Public Health I999;89:1359-64.

2. Olfson M, Gameroff MJ, Marcus SC, et al. National trends in the treatment of attention deficit hyperactivity disorder. Am J Psychiatry 2003;160:I07I-7.

3. Safer DJ, Zito JM, Fine EM. Increased methylphenidate usage for attention deficit disorder in the I99os. Pediatrics I996;98:1084-8.

4. Rushton JL, Whitmire JT. Pediatric stimulant and selective serotonin reuptake inhibitor prescription trends. Arch Pediatr Adolesc Med 200I;I55:560-5.

5. Miller AR, Lalonde CE, McGrail KM, et al. Prescription of methylphenidate to children and youth, I990-I996. CMAJ 200I;165:1489-94.

6. Romano E, Baillargeon RH, Hong-Xing W, et al. Prevalence of methylphenidate use and change over a two year period: a nationwide study of 2- to II-year old children. JPediatr 2002;14I:7I-5.

7. Hugtenburg JG, Heerdink ER, Egberts ACG. Increased psychotropic drug consumption by children in the Netherlands during I995-200I is caused by increased use of methylphenidate by boys. Eur J Clin Pharmacol 2004;60:377-9.

8. Vinker S, Vinker R, Elhayany A. Prevalence of methylphenidate use among Israeli children 1998-2004. Clin Drug Investig 2006;26:16I-7.

9. Berbatis CG, Sunderland VB, Bulsara M. Licit psychostimulant consumption in Australia, I984-2000: International and jurisdictional comparison. Med J Aust 2002;177:539-43.

Io. Zuvekas SH, Vitiello B, Norquist GS. Recent trends in stimulant medication use among US children. Am J Psychiatry 2006;163:579-85.

II. Miller A. Appropriateness of psychostimulant medication to children: theoretical and empirical perspectives. Can J Psychiatry 1999;44:1017-24

I2. Safer DJ. Are stimulants overprescribed for youths with ADHD? Ann Clin Psychiatry 2000;12:55-62.

13. Wolraich M. Increased psychotropic medication use: Are we improving mental health care or drugging our kids? Arch Pediatr Adolesc Med 2001;155:545.

I4. Charach A, Cao H, Schachar R, et al. Correlates of methylphenidate use in Canadian children: a cross-sectional study. Can J Psychiatry 2006;51:17-26.

I5. Sawyer MG, Rey JM, Graetz BW, et al. Use of medication by young people with attention-deficit/hyperactivity disorder. Med J Aust 2002;177:2I-5. 
I6. Harel EH, Brown WD. Attention deficit hyperactivity disorder in elementary school children in Rhode Island: associated psychosocial factors and medications used. Clin Pediatr (Phila) 2003;42:497-503

I7. Heuveline P, Timberlake JM, Furstenberg FF Jr. Shifting childrearing to single mothers: results from I7 Western countries. Popul Dev Rev 2003;29:47-7I.

I8. McLanahan S. Family, state and child well-being. Annu Rev Sociol 2000;26:703-6.

I9. McLeod JD. Shanahan MJ. Poverty, parenting and children's mental health. Am Sociol Rev I993;58:35I-66.

20. Strohschein L. Household income histories and child mental health trajectories. Health Soc Behav 2005;46:359-75.

2I. Amato PR. The consequences of divorce for adults and children. J Marriage Fam 2000;62:1269-87.

22. Fergusson DM, Horwood LJ, Lynskey MT. Parental separation, adolescent psychopathology and problem behaviors. J Am Acad Child Adolesc Psychiatry I994 33:II22-3I.

23. Najman JM, Behrens BC, Andersen A, et al. Impact of family type and family quality on child behavior problems: a longitudinal study. J Am Acad Child Adolesc Psychiatry 1997;36:1357-65

24. National Longitudinal Survey of Children and Youth user's guide - cycle 4. Ottawa: Statistics Canada and Human Resources and Social Development Canada; 2002.

25. Brownell MD, Yogendran MS. Attention-deficit hyperactivity disorder in Manitoba children: Medical diagnosis and psychostimulant treatment rates. Can J Psychiatry 200I;46:264-72.
26. Romano E, Baillargeon RH, Fortier I, et al. Individual change in methylphenidate use in a national sample of children aged 2 to II years. Can J Psychiatry 2005;50: I44-52.

27. Roman T, Schmitz M, Polanczyk G, et al. Attention-deficit hyperactivity disorder: study of association with both the dopamine transporter gene and the dopamine $\mathrm{D}_{4}$ receptor gene. Am J Med Genet 200I;105:47I-8.

28. Swanson JM, Flodman P, Kennedy J, et al. Dopamine genes and ADHD. Neurosci Biobehav Rev 2000;24:2I-5.

29. Johnston C, Mash EJ. Families of children with attention-deficit/hyperactivity disorder: review and recommendations for future research. Clin Child Fam Psychol Rev 200I; 4:183-207.

30. Woodard R. The diagnosis and medical treatment of ADHD in children and adolescents in primary care: a practical guide. Pediatr Nurs 2006;32:363-70.

31. Pryor J, Rodgers B, editors. Children in changing families: life after parental separation. Malden (MA): Blackwell; 200I.

Correspondence to: Dr. Lisa A. Strohschein, Assistant Professor, Department of Sociology, University of Alberta, Rm. 5-2I, Tory Building, Edmonton AB T6G 2H4; lisa.strohschein@ualberta.ca

In today's highly competitive and changing health care
market, an organization's success is built on the strength of
its medical staff. The right mix of physicians to meet
marketplace demands is crucial to a successful health care
organization. Quality health care recruitment is made easy
with CMA Careers job matching service and career
advertising.
Gain access to a highly skilled physician workforce
in seconds.
Post employment opportunities quickly and easily.
Advertise employment opportunities to 75,000
physicians.
Find your team... visit careers at cma.ca today!

